Fundamentals of Skin Biopsy. June $K$ Robinson. (Pp 124; £24.) 1986. Year Book Medical Publishers Inc. ISBN 0-8151-7312-1.

This A4 sized paper back is written by someone who does not state her qualifications and training in this field. This is important at a time when young dermatologists in the United Kingdom are being encouraged to take a greater interest in dermatological surgery. The borderline between dermatological and plastic surgery is poorly defined, and in this particular text there are a surprising number of black and white illustrations (some of indifferent quality) of facial procedures, including procedures around the lips and eyelid. Not all dermatologists would feel that these belong in such a text.

After three chapters on biopsy planning and anaesthesia the author describes punch, currettage, and elliptical excision biopsy techniques-in this order. This no doubt reflects the American enthusiasm for punch rather than elliptical biopsies. There then follow three useful sections on wound closure, wound improvement technique, and dressings, which include tables that are duplicated 40 pages on at the end of the book.

At $£ 24$ the book is relatively expensive. Young dermatologists and others who need to do good quality skin biopsies would learn as much, and probably considerably more, by spending one or two afternoons in an outpatient session with a plastic surgeon. There is little in the book of direct interest or importance to routine pathologists.

RONA M MACKIE

Biochemical Values in Clinical Medicine. 7th ed. RD Eastham. (Pp 473; £12.50.) Wright. 1985.

The last edition of this very useful guide to biochemical tests and interpretation was published in 1978. As a result of advances in knowledge and improved technology the pocket size edition has had to give way to a more substantial volume.

The introduction of a coding system indicating those tests required in an emergency, those done routinely, specialised tests and their cost, and those that are now obsolete has greatly added to its value.

This book will be of use as a rapid aide memoire to clinicians using the laboratory and to the chemical pathologist.

BRENDA SLAVIN
Notices

\section{ACP Symposium}

\section{THE FUTURE OF PATHOLOGISTS IN AN AGE OF COST CONTAIN- MENT AND TECHNOLOGICAL CHANGE}

The Association of Clinical Pathologists is organising a two day symposium with the above title to be held at the Barbican Centre, London on the afternoon of Thursday 16 and Friday 17 October 1986.

The Thursday session will cover the policy of the DHSS and its impact on the service specialities, the allocation of resources, the management of laboratories, and the need for information technology and performance indicators. The Friday dealing with each discipline in turnnamely, histopathology, clinical chemistry, microbiology, haematology, and forensic pathology. There will also be sessions dealing with the future of private practice and on the effects of training, teaching and research. Dr H Derman will speak on the changing role of the pathologist in America and the programme will probably include a similar lecture dealing with pathology in Europe.

Speakers from the United Kingdom will include Professor ED Acheson, Chief Medical Officer, DHSS; Professor B Clayton, President of the Royal College of Pathologists; Professor R Dyson, University of Keele; Mr B Edwards, Trent Regional General Manager; Dr PM Emerson, Consultant Haematologist; Professor FV Flynn, Consultant Chemical Pathologist; Dr AC Hunt, Consultant Histopathologist; Dr $\mathbf{H}$ Lommel, World Association of the Societies of Pathology; Dr AR Morley, Consultant Histopathologist; Dr JWG Smith, Director of the Public Health Laboratory Service; Mr C Spry, District General Manager, Newcastle Health Authority; Dr EW Walton, Consultant Histopathologist; and Mr GJ Wasserman, Assistant Under Secretary of State at the Home Office.

Further details may be obtained from: the Association of Clinical Pathologists, 57 Lower Belgrave Street, London SW1W 0LR. morning session will cover future trends
Fourth International Symposium on Morphometry in Morphological diagnosis

\author{
Royal Society of Medicine, \\ September 10-12, 1986
}

Although covering image analysis using large systems, many of the contributions will describe the use of small micro based systems suitable for use in a district general hospital. One session will be devoted to flow cytometry. The emphasis throughout will be on clinical applications and clinical usefulness. The programme includes invited expert guest speakers: Bahr (USA); Watson (UK); Ploem (Netherlands); Wied (USA); Aver (Sweden); Baak (Netherlands); Stenqvist (Sweden); and Collan (Finland).

There will also be a wide range of proferred papers and poster demonstrations, particularly on the applications of morphometry to gut, bone, breast, lymphoreticular and urogenital pathology. A pleasing feature of the proferred papers are the contributions correlating structure and function, which is an ideal aim for clinical pathologists.

A limited number of places now remain for attendance at the symposium. These will be allocated on a strictly first come, first served basis.

Further details may be obtained from: Miss Elaine Gill, Gill Medical, 429 Tamworth Road, Long Eaton, Nottingham NG10 3JT, England.

\section{ACP Locum Bureau}

The Association of Clinical Pathologists runs a locum bureau for consultant pathologists. would like to do locums and anyone $\Phi$ requiring a locum should contact Dr fo David Melcher, Histopathology Department, Sussex County Hospital, $\Phi$ Eastern Road, Brighton BN2 5BE.

\section{Correction}

On page 121 of $J$ Clin Pathol 1986;39 the designations of the authors were incorrecto Dr Cubitt works for the Department of Microbiology, Central Middlesex Hospitaf and Alison Brownell for the department of haematology, Central Middlesex Hospital.
Applicants with the MRC Path who 